\title{
A motivação na aprendizagem de uma língua estrangeira
}

\section{Rodrigo Almeida Reis de Vasconcelos}

Mestrando da Universidade Federal de Alagoas.

E-mail: rodrigo.vasconceloos@gmail.com.

Resumo: Este artigo originou-se a partir de pesquisa bibliográfica, com o objetivo de demonstrar como a motivação é importante e determinante no processo de aprendizagem de uma língua estrangeira. O propósito de compreender que cada indivíduo possui interesses distintos torna-se uma ferramenta essencial para 0 orientador, que tem como desafiadora funçāo ajudar a despertar as necessidades e desejos individuais da sua turma, conduzindo essa a um objetivo comum. Uma vez que se tornem claras as vantagens e utilidades de dominar uma língua estrangeira, 0 aluno poderá usar tal habilidade como "ferramenta" para alcançar os seus objetivos pessoais.

Palavras-Chave: motivaçāo; necessidade; aprendizagem; habilidade
Abstract: This article has its origin in the bibliographical research with the purpose of demonstrating how important and determinant motivation is in the foreign language learning process. The aim of comprehending that each individual has distinct interests becomes an essential tool for teachers, who have the challenging role of helping and stimulating individual desires and needs from each group, leading it to a common goal. Once the advantages of learning a foreign language become clear, the student may use such ability as an instrument for reaching personal achievements. 
- 


\section{Introdução}

Para a psicologia, a motivação é a força propulsora (desejo) por trás de todas as ações de um organismo. Segundo essa abordagem, a motivação é o processo responsável pela intensidade, direção e persistência dos esforços de uma pessoa para o alcance de uma determinada meta.

Ainda segundo a psicologia, a motivação se baseia em emoções, mais claramente falando, pela busca por experiências emocionais positivas e pelo desejo de evitar as experiências negativas, em que positivo e negativo são definidos pelo estado individual do cérebro, e não por normas sociais. Uma pessoa pode ser direcionada até a auto-mutilação ou a violência, caso o seu cérebro esteja condicionado a criar uma reação positiva a essas ações.

A "teoria contingencial da motivação" de Victor Vroom (1964) provê um modelo em que as pessoas "decidem" exercer o auto-controle para perseguirem um determinado objetivo. Esta teoria é, basicamente, uma tentativa de chegar a um método para saber como as pessoas decidiriam, racionalmente, se motivar ou não, através de um curso particular de ações. Segundo Vroom, o nível de produtividade individual depende de três forças básicas que atuam dentro do indivíduo: objetivos individuais; a relação que o indivíduo percebe entre produtivdade e alcance de seus objetivos individuais; e a capacidade de o indivíduo influenciar seu próprio nível de produtividade, à medida que acredita poder influenciá-lo. Para Chiavenato (2003), o modelo de motivação de Vroom apóia o modelo de expectação da motivação, que se baseia em objetivos intermediários e gradativos (meios) que conduzem a um objetivo final (fins).

De acordo com Vromm, é possível o indivíduo "estimular" a sua motivação em função dos seus objetivos, de forma racional e gradativa. Contudo, para Bergamini (1997), a motivação tem sido freqüentemente associada a tipos de comportamentos. Ainda segundo Bergamini, na motivação intrínseca, o desejo é o próprio centro 
motivador que conduz à ação; não sendo necessário, desta forma, criar comportamentos estimulantes para sentir-se motivado na direção das metas pessoais. Deste modo, todo movimento que o indivíduo faz na direção de comportamento que leve à motivação, é, na verdade, condicionamento ou motivação extrínseca (externa).

Segundo Morgan (2003), o "interesse” é o conjunto complexo de predisposições que envolvem objetivos, valores, desejos e outras orientações e indicações que impulsionam a pessoa a agir em uma, e não em outra, direção. O interesse está no centro da motivação. Seguindo a teoria de Morgan, o professor deve identificar o que desperta o interesse do grupo, canalizando-o, no sentido de melhorar o processo de aprendizagem da segunda língua. Não é possível motivar alguém (visto que essa é inerente ao ser humano), mas é possível estimulá-lo a ser motivado.

A partir de uma perspectiva cognitiva, Williams e Burden (1997) definem motivação como "um estado cognitivo ou emocional, que leva a pessoa a uma decisão consciente para agir para que um objetivo seja alcançado." Esta visão cognitiva da motivação coloca o indivíduo como responsável pelas suas ações. Ainda segundo os autores, o papel do professor, então, é de ajudar a fazer com que seus alunos tomem decisões apropriadas.

Para Gardner (1985), a motivação é a combinação de esforços, além do desejo de alcançar um objetivo que, no caso, é o aprendizado da língua, juntamente com atitudes favoráveis em relação ao aprendizado dessa. Para o autor, as atitudes positivas e a motivação estão relacionadas ao sucesso no aprendizado de uma segunda língua.

\section{Motivação intrínseca e extrínseca}

De acordo com Csikszentmihalyi e Nakamura (1989), há uma clara definição entre estes dois conceitos. Quando a razão para fazer uma ação é ganhar alguma coisa externa à atividade, como, por exemplo, passar em um exame, a motivação é extrìnseca. Quando a 
experiência de fazer algo gerar interesse e prazer, e a razão para tal está na própria tarefa, estamos diante da motivação intrínseca.

A motivação extrínseca vem a ser a influência dos fatores ambientais que movimentam as pessoas na execução de alguma coisa. Logo, essa nada mais é do que o condicionamento das pessoas. Essa prática nasceu a partir dos estudos dos behavioristas; contudo, mostrouse ineficiente, ao desconsiderar as habilidades e razões intrínsecas dos indivíduos. A motivação é algo bem diferente de movimentar uma pessoa até determinado objetivo (motivação extrínseca). A motivação, no sentido real da palavra, é intrínseca ao ser humano. Logo, o processo de aprendizagem em si será o "motor" motivador da pessoa. As primeiras teorias acerca da motivação consideram que as ações humanas são condicionadas pelas variáveis do ambiente, essa é a confusão feita entre motivação e condicionamento. Então, os fatores de satisfação que estão fora das pessoas só podem ser entendidos como reforços de comportamento, uma vez que, ao serem retirados, o comportamento que os estimulava cessará.

Em relação à aprendizagem de um segundo idioma, a metodologia de ensino, a forma de distribuição e adequação do ambiente onde são dadas as aulas, a capacidade didática do professor, a empatia entre orientador e alunos são aspectos que resultam em um eficiente processo de aprendizagem. Sabe-se que o ser humano possui necessidades e desejos individuais e formas individuais, também, de reagir à aprendizagem de algo novo. Um contexto externo propício a este processo de aprendizagem é essencial para despertar o desejo ou simpatia deste grupo pela matéria proposta. Estes aspectos externos são, desta forma, facilitadores para o processo de aprendizagem de cada aluno e complementares à motivação intrínseca de cada um.

É importante ressaltar como estas características dos ambientes freqüentados representam fatores externos 
relevantes. De acordo com Schütz (1993), se o ambiente em que o aprendizado da língua ocorrer for autêntico e proporcionar atividades voltadas aos interesses do aprendiz, o grau de motivação será alto. Porém, se o ambiente carecer de autenticidade, de elementos da cultura estrangeira, como, por exemplo, uma sala de aula com um número excessivo de alunos e um professor de proficiência limitada, em que as atividades nesse ambiente sejam ditadas por um plano didático predeterminado, em vez de centradas na pessoa e nos interesses do aprendiz, o grau de motivação será baixo. Desta forma, reforça-se a importância de um orientador perspicaz que consiga extrair o melhor de seus aprendizes através do estímulo às suas necessidades. A capacidade de compreender que cada aluno possui uma necessidade diferente do outro será determinante para o sucesso na aprendizagem.

Ainda segundo Schütz (1993), outra necessidade que se busca satisfazer (principalmente crianças, adolescentes e jovens adultos) é a de se explorar o desconhecido. Esta característica do ser humano também demonstra a importância de o ambiente de aprendizado da língua estar autenticado pela marca e presença da cultura estrangeira.

Oxford e Ehrman (1993) sugerem que "professores de uma segunda língua precisam identificar e compreender diferenças individuais significantes em seus alunos para fornecer a mais eficiente instrução possível." Ou seja, pessoas diferentes têm necessidades diferentes e a motivação, na verdade, é o interesse que a pessoa tem em fazer determinada coisa. Logo, um mesmo objetivoaprendizagem de uma segunda língua - terá diversos interesses para serem alcançados para diversas pessoas. Enquanto alguns alunos estarão em busca de satisfação pessoal, outros estarão habilitando-se para melhor desempenhar a sua tarefa, ou colocar-se no mercado de trabalho. Nesta hora, a empatia entre o orientador e sua turma e uma abordagem clara de como o segundo idioma pode impactar suas vidas fazem-se essenciais para 
despertar neste grupo o interesse por essa habilidade. É importante que o aluno faça a correlação entre a aprendizagem e suas metas pessoais.

Segundo Williams e Burden (1997), é essencial que o orientador compreenda a individualidade de cada aluno e consiga conduzir o grupo a alcançar seus interesses pessoais, a partir de um objetivo comum (processo de aprendizagem da segunda língua). Muitos alunos não conseguem fazer uma associação muito clara entre a utilidade do que está sendo aprendido com as aspirações pessoais, uma vez que muitos, ainda, não sabem que tipo de profissão irão seguir. Assim sendo, não sabem se posicionar no mercado de trabalho nem se conscientizam sobre a vantagem em ser capacitado no contexto social em que vivem.

Uma vez identificada essa falta de elaboração, por parte do aluno, dos seus anseios pessoais, faz-se imprescindível que o orientador desenvolva práticas que estimulem esta percepção, de forma a facilitar, para seu grupo, a importância de angariar conhecimentos para a concretização de metas pessoais, tais como: melhor posicionamento no mercado de trabalho, satisfação pessoal, status social, auto-estima, etc. Mais uma vez, o orientador tem um papel decisivo neste processo. É este que tem o "poder" de despertar em sua turma as suas necessidades potenciais, ajudando-a, através de informações, a descobrir o que realmente deseja, e desta forma, direcionando o grupo a um eficiente e eficaz processo de aprendizagem.

A disposição e a empolgação do professor são percebidas pelos aprendizes, de forma que esta postura do orientador torna-se um canal motivacional no aprendizado da língua estrangeira. Quando o orientador consegue externar os seus valores e sentimentos com relação à língua, instaura-se uma "ponte" de fácil comunicação entre aprendiz e instrutor que estimula aqueles alunos a participarem da aula em questão e interessarem-se pela matéria proposta. Desta forma, a 
postura do orientador torna-se um estímulo para o processo de aprendizagem, uma vez que o grupo tende a tomar como referência pessoas que despertem sua capacidade intelectual e senso crítico acerca do que está sendo aprendido.

\section{Aprendizagem}

Naturalmente, algumas pessoas têm maior facilidade em aprender um segundo idioma, enquanto outras têm extrema dificuldade (SCHÜTZ, 2004). Existem várias razões que influenciam neste processo de aprendizagem, tais como: idade (quanto mais cedo se inicia este processo, mais fácil é, pois o ritmo de assimilação das crianças é bem mais rápido): semelhanças com a língua "materna" (para os ocidentais aprender línguas orientaisé mais difícil e vice-versa); capacidade auditiva (pessoas que têm boa acuidade auditiva assimilam e reproduzem a língua aprendida com maior facilidade); características da personalidade (elevada auto-estima, desinibição, criatividade, empatia, curiosidade são aspectos positivos neste processo, por exemplo. Enquanto a baixa autoestima, a inibição, a antipatia pela língua e sua cultura são aspectos negativos); finalmente, há a questão da memória (capacidade de reter informações), dentre outros itens que também devem ser considerados.

A motivação vem a ser um dos fatores que facilitam o processo de aprendizagem, porém, muitas vezes, não se leva em conta a motivação do aluno e ficase preso a métodos antiquados e pouco práticos, e o aluno começa a criar certa resistência ao segundo idioma, uma vez que não consegue identificar a relação entre esta nova habilidade com as suas necessidades.

Vencer a desmotivação do aluno criada a partir de uma metodologia pouco eficiente, por exemplo, é um obstáculo que o orientador deve superar. Reconhecer as aptidões naturais da sua turma e identificar as resistências dessa para com a nova língua serão de suma importância 
para que o aluno possa vir a sentir-se motivado neste processo, facilitando não só a sua aprendizagem, como a abordagem do professor.

\section{A motivação na aprendizagem}

A motivação é uma força interior propulsora de decisiva importância no desenvolvimento do ser humano. $\mathrm{Na}$ aprendizagem em geral, o ato de se aprender línguas é ativo e não passivo (SCHÜTZ, 2003), pois, trata-se de adquirir uma habilidade. Não é apenas o professor quem ensina ou o método que funciona; é o aluno, também, que aprende. Por isso, a motivação do aprendiz, no aprendizado de línguas, é um elemento imprescindível.

A origem da motivação é sempre o desejo de satisfazer às necessidades. O ser humano é um animal social por natureza e, como tal, tem a necessidade de se relacionar com os outros de seu ambiente. Esta tendência de se integrar é um dos fatores internos ativador da motivação para muitos dos atos de uma pessoa. Por exemplo, se estivermos em um ambiente caracterizado pela presença de uma língua estrangeira, naturalmente teremos uma forte e imediata motivação para assimilarmos essa "ferramenta" que nos permite interagir no ambiente, dele participar e nele atuar. Por esta razão, aprender uma língua fora do seu ambiente pode tornar-se um obstáculo, uma vez que o aluno não consiga identificar uma finalidade prática, muitas vezes, para esse aprendizado.

Desta forma, reforça-se a importância de um ambiente propício voltado para a melhor assimilação da segunda língua, assim como a empatia e autoconfiança do orientador, ao passar este conhecimento para a sua turma. Além disso, ele deve detectar, nesta turma, quais anseios predominam com relação à aquisição desta nova habilidade ou como este conhecimento pode ajudá-los a alcançar metas pessoais futuras.

Uma vez que esteja clara, para a turma, a utilidade deste processo de aprendizagem, e o ambiente externo 
seja adequado para tal assimilação, pode-se perceber como a motivação inerente a cada um ajudará, significativamente, e por que não dizer?, decisivamente, para o sucesso deste grupo.

\section{Desmotivação}

Se a motivação se origina no desejo de satisfazer uma necessidade, não havendo necessidade, não haverá motivação. Pelo contrário, a reação normal da pessoa, quando submetida a uma atividade não resultante de um desejo de satisfazer uma necessidade, é a desmotivação (SCHÜTZ, 2003).

Por exemplo, um ambiente de sala de aula voltada ao ensino formal de uma língua estrangeira, sem a presença de bom representantes dessa língua e de sua cultura, é um exemplo de ambiente que não evidencia necessidade, não produz motivação e não estimula o aprendizado.

Podem-se encontrar, atualmente, no ensino de inglês, inúmeros fatores desmotivadores, como: salas de aula com muitos alunos, professores com proficiência limitada, cobrança através de exames de avaliação com questões truculentas que nada avaliam, repetição oral mecânica, etc. Esses fatores desmotivadores podem ser observados tanto na rede de escolas de ensino médio, na qual o ensino de inglês ficou estagnado no método de tradução e gramática do início do século, como nos cursos particulares de línguas, que ficaram estagnados no método audiolingüístico dos anos 60 (SCHÜTZ 2003). Nem um nem outro método acima referido mostra resultados imediatos motivadores nem permite que o aluno alcance a proficiência desejada, gerando, desta forma, certa frustração que, em maior ou menor grau, destrói a motivação.

A empatia entre o professor e o grupo, assim como a sua didática e o entusiasmo pela língua estrangeira, é facilmente percebida pelos seus aprendizes que, quando não identificam estes atributos no professor, não conseguem 
enxergar a finalidade prática desta nova língua e acabam por se desmotivar neste processo. Alunos que já vêm de tentativas frustradas de aprender um segundo idioma terão, certamente, maior resistência para avaliar este processo como válido e útil. É importante, desta forma, desmistificar equivocados conceitos nutridos pelos alunos com relação à língua estrangeira e "quebrar" a resistência trazida por muitos desses, em função desta primeira má impressão. Mostrar uma nova proposta de aprendizagem em que se leva em conta, sobretudo, as suas necessidades individuais e proporcionar um ambiente externo adequado para desenvolver esta habilidade são, sem dúvida, fatores de sucesso para ambos (aluno e professor).

Aquele aprendiz que não se identifica com a cultura estrangeira, ou que, às vezes, até a despreza (normalmente por falta de maiores informações a respeito da mesma ou por informações estereotipadas que o professor não soube corrigir) estará desmotivado a aprender a nova língua. Toda resistência ao processo de aprendizagem causada por conceitos equivocados pode ser um obstáculo difícil de sobrepor, caso o orientador não veja a tempo tal associação nutrida pelo aluno e a desmistifique, de forma a proporcionar ao potencial aprendiz possibilidade de interessar-se pela aquisição desta habilidade.

A pessoa que tiver oportunidade de ter contato com a língua estrangeira, em situações reais de comunicação, em ambientes autênticos dessa língua e de sua cultura, onde a língua está presente como meio de interação e não ausente (ministrada em doses pequenas e amargada pela repetição mecânica descontextualizada ou pela dissecação gramatical), vai certamente ser bem sucedida.

\section{Conclusão}

A motivação é um dos aspectos mais importantes para aquisição de uma segunda língua. Se os alunos são motivados a aprender uma segunda língua, é mais provável 
que os mesmos sejam bem sucedidos na busca dos seus objetivos pessoais.

Existem muitos fatores internos e externos que podem contribuir para a motivação do estudante, como o interesse, a aptidão, a atitude, o método de ensino, o professor, as ambições profissionais, etc. Contudo, educadores devem estar atentos a estes aspectos para acionar a motivação dos estudantes, pois, a motivação, como já foi citada acima, pode ser responsável pelo o sucesso do estudante, no processo de aprendizagem.

É importante enfatizar que o interesse do estudante é um fator motivacional e este se relaciona com o sucesso (GARDNER, 1985). O estudante interessado geralmente arrisca-se mais e pergunta mais sobre a língua a ser aprendida. Embora o interesse seja um fator motivacional interno, existem situações externas que podem contribuir com o estímulo e aumentar o envolvimento no processo de aprendizagem. Tais estímulos podem ser explorados por professores através de lições dadas com temas relacionados às vidas dos estudantes e as suas idades.

É extremamente importante para o professor dar o valor essencial para os seus próprios sentimentos em relação à língua. O entusiasmo do professor é significativo para fazer o estudante perceber a importância da aprendizagem da segunda língua.

Os alunos podem perceber certa incoerência entre a teoria e a prática. Bergamini (1997, p. 92) afirma que é importante manter a alta motivação dos alunos, assim como no primeiro dia de aula, através da criação de um ambiente agradável de estudos. Portanto, o entusiasmo do professor pode ser essencial para o sucesso em uma aprendizagem de segunda língua. 


\section{Referências}

BERGAMINI, Cecília W. et al. Psicodinâmica da vida organizacional: motivação e liderança. 2 ed. São Paulo: Atlas, 1997

CHIAVENATO, Idalberto. Administração de recursos humanos.

3. ed. São Paulo: Mc-Graw-Hill, 1987.

CSIKSZENTMIHALYI, Mihaly, M.; Nakamura, J. The dynamics of intrinsic motivation: a study of adolescents. In: AMES, C.; AMES, R. (Orgs.). Research on motivation in education. Goals and Cognitions. New York: Academic Press, 1989.

ELLIS, Rod. Second language acquisition. Oxford: Oxford University Press, 1997.

GARDNER R. C. LAMBERT, W. E. Attitudes and motivation in second language learning. Rowley, Massachusetts: Newbury, 1972.

MORGAN, Gareth. Imagens da organização. São Paulo: Atlas, 1996.

OXFORD, R. \& EHRMAN, M. Second language research on individual differences. Annual review of applied linguistics, 1993, 13, p. $182-205$.

SCHÜTZ, Ricardo. Motivação e Desmotivação no Aprendizado de Línguas. English Made in Brazil. Disponível em <http:// www.sk.com.br/sk-motiv.html>. Acesso: 10 de novembro de 2003.

O que é talento para línguas? Disponível em http:// www.sk.com.br/sk-talen.html. Acesso: 20 de junho de 2004.

VROOM, Victor H. Work and motivation. New York: Wiley, 1964.

WILLIAMS, Marion; BURDEN, Robert L. Psychology for language teachers: a social constructivist approach. Cambridge: Cambridge University Press, 1997. 